\title{
FOUCAULT E MERLEAU-PONTY: UM BREVE ENSAIO SOBRE AS RELAÇÕES ENTRE CORPO, MEIO AMBIENTE E EDUCAÇÃO
}

Deborah Dornellas Ramos ${ }^{\mathrm{i}}$

\begin{abstract}
Resumo: Este artigo se propõe a discutir as possíveis relações entre corpo, meio ambiente e educação, considerando as contribuições de Foucault e Merleau-Ponty. Merleau-Ponty contribuiu para uma revisão das noções de corpo e de corporeidade, considerando seu papel na constituição do sujeito mediante sua experiência como ser-no-mundo. Partindo de uma perspectiva foucaultiana, pode-se dizer que esse processo se realiza imerso nas relações de poder, as quais se refletem na subjetividade do sujeito e no seu corpo, sendo instrumentalizadas, no contexto escolar, mediante as concepções de educação e de mundo. As repercussões dessa dinâmica sobre as formas como nos relacionamos com o mundo pode ser mais trabalhada nas escolas pela Educação Ambiental como espaço para se experimentar a carne, considerando a continuidade entre o corpo e o mundo.
\end{abstract}

Palavras chave: Corpo; Relações de poder; Educação; Meio ambiente.

\section{FOUCAULT AND MERLEAU-PONTY: A BRIEF ESSAY ON THE RELATIONSHIP BETWEEN THE BODY, THE ENVIRONMENT AND EDUCATION}

\begin{abstract}
This research aims to discuss the possible relationships between the body, the environment and education, considering the contributions of Foucault and Merleau-Ponty. Merleau-Ponty influenced the notion of body and of corporeality, considering its role in the constitution of the subject through his experience as being-in-the-world. Starting from a Foucault's perspective, it is possible to say that this process is configured between the power relations, which are also reflected in the subjectivity of the subject and in his body, being orchestrated, in the school context by the conceptions of education and world. The repercussions of his dynamic in the ways in which we relate to the world can be further worked in the school context by Environmental Education as a space to experience the flesh, considering the continuity between the body and the world.
\end{abstract}

Keywords: Body; Power relations; Education; Environment.

\section{Corpo e corporeidade: contribuições de Merleau-Ponty}

O conceito de corporeidade remete a uma compreensão do corpo como unidade indivisível, plástica e imbricada no mundo, considerando a complexidade, a imprevisibilidade e o paradoxo_enquanto fatores inerentes à própria existência humana. Essa natureza ambígua do corpo nos exige compreendê-lo como plural e, ao mesmo tempo, um só, entrelaçado com o mundo, com a cultura e dialogando com outros corpos, em uma relação recíproca que é geradora de múltiplos sentidos para ambos. Isso implica em uma 
compreensão de corporeidade que contemple o corpo não apenas a partir de um único aspecto ou sentido da existência, mas que abranja vários outros, considerando a existência simultânea entre eles (NEUENFELDT; MAZZARINO, 2016; PORPINO, 2018).

Pode-se dizer que essa concepção sistêmica e dialógica que se tem atualmente acerca da corporeidade foi muito influenciada pelo pensamento de Merleau-Ponty (1999), que enxergava o corpo como o nosso modo próprio de ser-no-mundo, ou seja, o corpo é o que sou. Para o filósofo, sentir, pensar e agir se fundem na experiência do homem como ser-no-mundo. E o mundo não é somente aquilo que penso, mas aquilo que eu vivo, que experimento, haja vista que o significado das coisas se constrói nas relações entre o eu, o outro e o mundo. Ainda para Merleau-Ponty (1999), é por meio do corpo que os fenômenos são sentidos, percebidos, compreendidos e significados pelos sujeitos, visto que até mesmo a formação dos processos cognitivos e a vivência do contato direto com o mundo passam pelo corpo:

Mas nosso corpo não é apenas um espaço expressivo entre todos os outros. Este é apenas o corpo constituído. Ele é a origem de todos os outros, o próprio movimento de expressão, aquilo que projeta as significações no exterior dando-lhes um lugar, aquilo que faz com que elas comecem a existir como coisas, sob nossas mãos, sob nossos olhos. [...] O corpo é nosso meio geral de ter um mundo. Ora ele se limita aos gestos necessários à conservação da vida e, correlativamente, põe em torno de nós um mundo biológico; ora brincando com seus primeiros gestos e passando de seu sentido próprio a um sentido figurado, ele manifesta através deles um novo núcleo de significação: é o caso dos hábitos motores como a dança. [...] A significação visada não pode ser alcançada pelos meios naturais do corpo; é preciso então que ele se construa um instrumento, e ele projeta em torno de si um mundo cultural. (p. 203)

O corpo, nessa perspectiva, constitui o elo que se estabelece nas relações entre o homem e o mundo, a sociedade, a cultura, a natureza, sendo a própria existência humana vista como um contínuo indivisível desses aspectos (SANTOS, 2016). O homem e o mundo pertencem à mesma vida, sendo o corpo visto, portanto, como carne do mundo. E a carne é mais que um corpo vivido, é dinâmica; não é mera materialidade inerte, mas, sim, a incorporação recíproca do meu corpo no mundo e do mundo em mim (MERLEAU-PONTY, 1992). Dessa forma, pode-se dizer que o homem e o mundo fazem parte da mesma carne e constituem um ao outro. E o nosso contato conosco sempre se faz por meio de uma cultura que nos proporciona o conhecimento e a construção de nós mesmos, inclusive como sujeitos, a partir da referência do outro como corpo-próprio e ser-no-mundo. De acordo com Merleau-Ponty:

[...] não vivemos a princípio na consciência de nós mesmos - nem mesmo, aliás, na consciência das coisas - mas na experiência do outro. Só sentimos que existimos depois de já ter entrado em contato com os outros, e nossa reflexão é sempre um retorno a nós mesmos que, aliás, deve muito à nossa frequentação do outro. (MERLEAU-PONTY, 2004, p. 49) 
A compreensão de Merleau-Ponty sobre o corpo como um todo indivisível e imbricado no mundo faz contraponto à tradição racionalista, cuja visão dualista predominou por muito tempo na história da filosofia, estabelecendo cisões entre aspectos que, na verdade, não se encerram em si, tais como: as relações mente/corpo, razão/emoção, homem/sociedade e seres humanos/natureza (LÓPEZ-LÓPEZ; GALDINO, 2020; NEUENFELDT; MAZZARINO, 2016; PORPINO, 2018; SANTOS, 2016). Ressalta-se que o Racionalismo constitui a origem da tradição científica positivista, baseada em relações de causa e efeitos e no fracionamento das áreas do conhecimento, o que se reflete, ainda hoje, na dificuldade de pensarmos de forma não linear.

A frase "penso, logo existo" pode ser vista como representativa da corrente de pensamento racionalista, a qual atribui a substância do homem ao pensar, contrapondo-a ao corpo, que é concebido como matéria e vinculado ao plano do sensível. Nessa perspectiva, o corpo estaria a serviço da razão enquanto instância superior e mais valorizada da nossa existência. Consequentemente, toda informação proporcionada pelas experiências do corpo deveria ser vista com ressalvas, pois, apesar das evidências, estaria sujeita às limitações dos nossos sentidos e da nossa percepção. Por sua vez, o saber metódico, com suas medidas e experimentos controlados, seria o único capaz de "nos libertar" das ilusões dos nossos sentidos e nos fazer chegar à verdadeira natureza das coisas.

Em sua crítica a essa tradição de pensamento, Merleau-Ponty (2004) salienta que o concreto e o sensível conferem à ciência a tarefa de uma elucidação interminável porque a complexidade e a incompletude do homem e do mundo precisam ser consideradas no processo de construção do conhecimento, o que expõe as limitações da tradição científica clássica. Para o filósofo:

Em ciência, não podemos nos vangloriar de chegar, pelo exercício de uma ciência pura e não situada, a um objeto livre de qualquer vestígio humano [...]. Isso em nada diminui a necessidade da pesquisa científica e combate apenas o dogmatismo de uma ciência que se considerasse o saber absoluto e total. Isso simplesmente faz justiça a todos os elementos da experiência humana e, em particular, à nossa percepção sensível. (p. 07)

Ainda segundo Merleau-Ponty (2004), a ideia de uma inteligência sem corpo deve ser substituída pela compreensão do "homem como um espírito com um corpo, que só alcança a verdade das coisas porque seu corpo está como que cravado nelas" (p. 18). A partir dessa perspectiva, o filósofo defende que a realidade concreta precisa ser considerada como um contexto do qual fazemos parte e que também faz parte de nós, que possui relações com nossas particularidades corporais, com nossas formas de ser-no-mundo, visto que somos carne do mundo. E esse mundo só nos é acessível por meio do nosso corpo e é revestido de atributos humanos que fazem dele também uma mescla de corpo e de espírito. 
Compreende-se, portanto, que posturas rígidas e maniqueístas não comportam a noção do humano como um ser mutante, com suas ambiguidades e incompletudes, o que implicaria em transitar por caminhos que, aparentemente, são opostos, não “se cruzam” (LÓPEZ-LÓPEZ; GALDINO, 2020; NEUENFELDT; MAZZARINO, 2016). Essa transitoriedade característica do humano ganha notoriedade no pensamento de Foucault (2009; 1987; 1984), quando discute as relações de poder e seus reflexos sobre o corpo.

\section{Corpo e educação: contribuições de Michel Foucault}

Foucault (1984) se distancia dos pensadores ditos estruturalistas ao defender que as relações de poder não podem ser reduzidas à oposição dualista, cristalizada, entre opressor e oprimido. Para Foucault (1984; 1987), as relações de poder se estabelecem como em uma espécie de jogo, no qual o poder transita de uma parte a outra, sendo disputado, mesmo que tenda a prevalecer mais com uns que com outros. Isso significa pensar essas relações como uma rede que se distribui de forma capilarizada e se dissemina no tecido social, compreendendo não só as relações entre os diferentes grupos sociais, mas também aquelas que se estabelecem no interior dos próprios grupos, o que varia de acordo com os diferentes momentos e situações. Sendo vistas dessa forma, as relações de poder implicam resistência, contestação, negociação; do contrário, não podem ser consideradas relações de poder, mas, sim, de violência.

De fato, aquilo que define uma relação de poder é um modo de ação que não age direta e imediatamente sobre os outros, mas que age sobre sua própria ação. Uma ação sobre a ação, sobre ações eventuais ou atuais, futuras ou presentes. Uma relação de violência age sobre um corpo, sobre as coisas: ela força, dobra, quebra, destrói; ela fecha todas as possibilidades; não tem, portanto, junto a si, outro polo senão o da passividade; e, se encontra uma resistência, a única escolha é tentar reduzi-la. Uma relação de poder, ao contrário, se articula sobre dois elementos que lhe são indispensáveis para ser exatamente uma relação de poder: que o 'outro' (aquele sobre o qual ela se exerce) seja reconhecido e mantido até o fim como o sujeito de ação; e que se abra, diante da relação de poder, todo um campo de respostas, reações, efeitos, invenções possíveis (FOUCAULT, 2009, p. 243).

Nessa perspectiva, o corpo é, ao mesmo tempo, aquele que exerce poder e se submete a ele. O corpo, a nossa forma de ser no mundo, termina se configurando na medida em que faz parte dessas relações, na medida em que produz e é produzido por elas (MALAVOLTA; RIGUE; BIAZUS, 2020; PORPINO, 2018). Assim como as relações de poder se espraiam, se disseminam pelo tecido social, elas também o fazem nos corpos dos sujeitos, o que fica visível, por exemplo, na postura dos que exercem o poder, dos que são “autoridade", e dos que estão submetidos aos mesmos, os quais, segundo Foucault (1987), se revelam pelos seus “corpos dóceis", que podem ser submetidos, utilizados, transformados e aperfeiçoados, ou seja, podem ser disciplinados: 
O corpo humano entra numa maquinaria de poder que o esquadrinha, o desarticula e o recompõe. Uma 'anatomia política', que é também igualmente uma "mecânica do poder" está nascendo; ela define como se pode ter domínio sobre o corpo dos outros, não simplesmente para que façam o que se quer, mas para que operem como se quer, com as técnicas, segundo a rapidez e a eficácia que se determina. A disciplina fabrica assim corpos submissos e exercitados, 'corpos dóceis' (FOUCAULT, 1987, p. 135).

Destaca-se ainda que a educação, mediante o exercício do poder, também se torna produto e produtora/reprodutora das relações de poder que se estabelecem numa determinada sociedade, inserida em uma determinada cultura (FOUCAULT, 1984; 1987). Para tanto, as instituições educacionais, por exemplo, exercem esse poder mediante as concepções que norteiam as suas práticas educativas, pelos discursos que defendem e pelas formas como exercem a disciplina:

Jean Baptiste de La Salle imaginava uma classe onde a distribuição espacial pudesse realizar ao mesmo tempo toda uma série de distinções: segundo o nível de avanço dos alunos, segundo o valor de cada um, segundo seu temperamento melhor ou pior, segundo sua maior ou menor aplicação, segundo sua limpeza, e segundo a fortuna dos pais. Então a sala de aula formaria um grande quadro único, com entradas múltiplas, sob o olhar cuidadosamente "classificador" do professor (FOUCAULT, 1987, p. 144).

Hoje em dia, outras regras, teorias e conselhos - científicos, ergométricos e psicológicos, por exemplo - são produzidos/reproduzidos pelas escolas em virtude da necessidade de adequação às novas condições, instrumentos e práticas educativas (LOURO, 2014; MALAVOLTA; RIGUE; BIAZUS, 2020). Todavia, pode-se dizer que, sob novas formas, a escola continua imprimindo sua "marca distintiva" sobre os sujeitos, mediante currículos, normas, procedimentos de ensino, teorias, linguagem, materiais didáticos e processos de avaliação:

Currículos, regulamentos, instrumentos de avaliação e ordenamento dividem, hierarquizam, subordinam, legitimam ou desqualificam os sujeitos. Tomaz Tadeu da Silva (1996, p. 168) afirma que o 'poder está inscrito no currículo'. Como já observamos, a seleção dos conhecimentos é reveladora das divisões sociais e da legitimação de alguns grupos em detrimento de outros. Para Tomaz, o poder é precisamente aquilo que divide o currículo - que diz o que é conhecimento e o que não é — e aquilo que essa divisão divide (LOURO, 2014, p. 85).

Portanto, mediante múltiplos e discretos mecanismos, o jogo das relações de poder se reflete na vigilância que se faz dos comportamentos e dos corpos, na forma como se estabelecem as relações hierárquicas entre os próprios conteúdos, nas diferenças quanto à distribuição do tempo e da ocupação dos espaços nas escolas, bem como na prioridade que é dada a determinadas disciplinas ou não, por exemplo. Partindo do pressuposto que estamos discutindo sobre corpo e educação, poderíamos questionar: seria possível promover outras formas de experimentar o corpo no contexto educacional? 
Sob essa ótica, em relação às escolas, especificamente, Lucena e Sousa (2009), bem como Nóbrega (2005), ponderam que o corpo não tem ocupado espaços significativos na grade curricular, ficando, geralmente, restrito às aulas semanais de Educação Física, disciplina que é concebida, ainda, numa perspectiva prática, como sinônimo de exercitação física, sendo marginalizada do contexto intelectual. Nos casos em que há um interesse maior dos alunos pelas atividades relacionadas ao corpo, é preciso buscarem aulas extras, pelas quais precisam pagar, como um produto, um bem de consumo, haja vista que não fazem parte do currículo regular. Nesse contexto, o conhecimento sensível sobre as linguagens do corpo, as formas de se colocar no mundo e de fazer dele experiência são concebidas, no máximo, como um complemento da atividade vista como racional, esta, sim, considerada produtiva e valorizada, o que fica evidenciado, também, no universo do trabalho, quando levados em conta aspectos, tais como a remuneração e o reconhecimento social.

Vale ressaltar que o corpo também termina sendo concebido e disciplinado na perspectiva da utilidade (FOUCAULT, 1987). Segundo Nóbrega (2005), o corpo, mesmo no pouco tempo e espaço que ocupa nas escolas, é trabalhado levando-se em consideração padrões de controle e de rendimento, fazendo com que os alunos não tenham oportunidades de obter um conhecimento vivencial de si como corporeidade e do porquê dos movimentos executados, o que faz, muitas vezes, com que não tenham significado algum para os mesmos. Há, portanto, uma ausência da compreensão do corpo em sua pluralidade e em sua complexidade. Nessa perspectiva, Merleau-Ponty (2004) afirma que o corpo é o que sou; é o que eu vivo, o que eu experimento e o que eu penso, não podendo ser resumido a um único aspecto ou sentido da existência, pois precisa ser compreendido como espaço onde existimos e experimentamos o mundo com o qual somos carne e estamos entrelaçados, assim como ocorre com a cultura e com a natureza.

Ainda é preciso salientar que um dos sentidos que é dado ao corpo está associado aos padrões culturalmente vigentes do que seria o "corpo belo", sendo a escola também produto e produtora/reprodutora desses padrões. Contudo, o corpo e o belo, além de plurais, se modificam; são transitórios (OLIVEIRA; MEDEIROS, 2014; SILVA; PORPINO, 2010). Portanto, o espaço da escola poderia ser melhor aproveitado para o desenvolvimento do senso estético, o que compreende a experiência estética como um todo e a apreciação do diferente, para além dos padrões que refletem formas preestabelecidas de se colocar no mundo e de se relacionar com ele (PORPINO, 2018).

Acerca da vivência estética, Porpino (2018) afirma que esta consiste na experiência da beleza, da sensibilidade, da descoberta do sentido na vida cotidiana. Compreender a experiência estética e vivê-la plenamente consistiria, portanto, em poder abrir novos caminhos para a compreensão não fragmentada da existência humana, transgredindo a visão racionalista e levando à educação uma concepção de ser humano que possa transgredir essa visão dicotomizada, ainda predominante. 
Diante desse contexto, ainda é válido lembrar que, para Foucault (1987), os jogos e relações de poder não devem ser vistos apenas a partir de uma perspectiva negativa, haja vista que esses mesmos também são responsáveis por nos impelir, nos instigar, nos impulsionar a subverter a ordem vigente. Destaca-se, nesse sentido, que a educação se constitui como espaço privilegiado para que a experiência dessas relações seja revivida, recriada e ressignificada, favorecendo a formação de seres mais conscientes de si como corpos-próprios e das suas relações com o mundo.

\section{Corpo e Educação Ambiental}

No que diz respeito às nossas relações com o mundo, Lucena e Sousa (2009) afirmam que a tradição de pensamento dualista e o processo de "individualização" têm levado as pessoas a se enxergarem de forma "descolada" do mundo em que vivem, como seres distintos e independentes dos seus grupos, de seus contextos socioculturais, assim como do meio ambiente, o que, partindo do modo como Merleau-Ponty (1999) compreende a corporeidade, consiste em um contrassenso, na medida em que o corpo não se encerra em si. Para Merleau-Ponty:

A experiência revela sob o espaço objetivo, no qual finalmente o corpo toma lugar, uma espacialidade primordial da qual a primeira é apenas o invólucro e que se confunde com o próprio ser do corpo. Ser corpo, nós o vimos, é estar atado a um certo mundo, e nosso corpo não está primeiramente no espaço: ele é no espaço (MERLEAU-PONTY, 1999, p. 205).

Dessa forma, é preciso lembrar que o corpo deve ser entendido na sua relação de continuidade com o mundo, considerando-se que o homem e a natureza, o corpo e o meio ambiente, interagem entre si e se constituem na mesma carne, numa relação não linear e sistêmica (LUCENA; SOUSA, 2009; SANTOS, 2106). Nesse sentido, um espaço educativo no qual o corpo pode ser trabalhado, a partir dessa perspectiva, consiste na Educação Ambiental, disciplina que vê o mundo a partir das inter-relações e da interdependência entre os diversos elementos na manutenção e na constituição da vida. Educar, nessa perspectiva, implica considerar não só que se vive uma crise ambiental, mas também, civilizatória, que exige experimentarmos de outras maneiras as nossas relações com o meio ambiente e com a natureza, as quais também podem ser compreendidas à luz dinâmica das relações de poder.

Segundo Neuenfeldt e Mazzarino (2016), o homem não se enxerga como parte integrante do meio em que vive, entendendo que a natureza está a seu serviço, enquanto recurso que deve ser explorado de forma útil pela sociedade. Pode-se dizer que essa concepção consiste em mais uma herança do dualismo racionalista. Isso porque, partindo do pressuposto que o sujeito seria o cogito, e o mundo, seu objeto, o 
homem passa a se ver como distinto de tudo aquilo que seria próprio da natureza, concebida como oposto do homem "racional".

No que tange ao posicionamento de Merleau-Ponty acerca da relação entre o cogito e a natureza, Saenz (2006) afirma que, para o filósofo, a natureza não é o oposto da consciência, visto que esta é corporal e perceptiva, o que remete à própria natureza. E essa natureza, percebida, sentida, experimentada corporalmente, seria o ponto de encontro entre o que se poderia chamar de natureza exterior e natureza interior. Desse modo, não existiria uma relação de oposição, mas, sim, de síntese, de continuidade.

Destarte, faz-se notória a necessidade de empreendermos uma mudança de paradigma no que tange à relação homem-natureza. Contudo, não basta partir da visão utilitarista de preservar a natureza com o propósito de garantir a exploração desse mesmo recurso no futuro. É necessário considerar as contribuições da Educação Ambiental para reconciliar a nossa relação com a natureza e com o mundo, conscientizando as pessoas de que, uma vez que estejam inseridas em um determinado meio - o que inclui, o social —, elas são responsáveis, direta ou indiretamente, pela sustentabilidade do mesmo, o que compreende, tanto a natureza em si, quanto as comunidades onde se vive.

Nessa perspectiva, é preciso destacar que o corpo consiste no elo-chave dessa relação. Para Saenz (2006), ao fazer do corpo e do mundo manifestações diferenciadas da mesma carne, Merleau-Ponty rompe com a oposição homem/natureza. Essa consciência da continuidade ontológica entre o homem e o mundo se adquire por meio da experiência do corpo vivido em sua coexistência com as coisas do mundo e com a natureza. Isso porque é no corpo que a experiência nos toca e as experiências com o meio ambiente são capazes de nos sensibilizar para a experiência da carne.

É preciso ressaltar, todavia, que a experiência, aqui, precisa ser compreendida para além do paradigma científico racionalista que, na tentativa de homogeneizar/universalizar as experiências sensoriais (associadas ao corpo e aos sentidos de cada um), terminou reduzindo as mesmas ao controle e ao planejamento dos experimentos empíricos. Ao contrário, a experiência precisa ser valorizada na ciência e na educação justamente por aquilo que ela é; pelo seu caráter único e subjetivo, que se faz produtor de significados, sentidos e afetos para os sujeitos, sobretudo os que aprendem com elas. As experiências nos mobilizam, nos levam à reflexão, nos desacomodam. Nesse sentido, Merleau-Ponty afirmava:

Sistema de potências motoras ou de potências perceptivas, nosso corpo não é objeto para um 'eu penso': ele é um conjunto de significações vividas que caminha para seu equilíbrio. Por vezes forma-se um novo nó de significações: nossos movimentos antigos integram-se a uma nova entidade motora, os primeiros dados da visão a uma nova entidade sensorial, repentinamente nossos poderes naturais vão ao encontro de uma significação mais rica que até então estava apenas indicada em nosso campo perceptivo ou prático, só se anunciava em nossa experiência por uma certa falta, e cujo advento reorganiza subitamente nosso equilíbrio e preenche nossa expectativa cega (MERLEAU-PONTY, 1999 p. 212). 
Ainda em relação às nossas experiências sensoriais, pode-se dizer que, nesse processo de "intelectualização" e "descorporalização", o homem foi perdendo a comunicação com o próprio corpo (GONÇALVES, 2001; LUCENA; SOUSA, 2009; PORPINO, 2018) e do corpo com o mundo, em virtude do excesso de estímulos, de trabalho e outras prioridades que ocupam os nossos dias e, no final, não nos permitem parar para cultivar o ócio criativo, por exemplo, nem tampouco apreciar e nos deixar tocar/emocionar pelas experiências estéticas proporcionadas pela arte, pela natureza e pelo próprio corpo.

Nessa perspectiva, educar para que possamos resgatar esse caráter sensível da nossa existência, a partir da valorização das nossas relações com o corpo e com o mundo, é algo que pode ser trabalhado nas próprias escolas, por exemplo, de forma transversal. No que tange aos temas na educação que compreendem as nossas relações com o mundo e a sociedade, é válido ressaltar que a Educação Ambiental está prevista nos Parâmetros Curriculares Nacionais - PCNs (BRASIL, 1997) enquanto tema transversal, que deve ser abordado a partir das suas relações com as diversas disciplinas.

A transversalidade da Educação Ambiental se dá pelo fato dessa disciplina desafiar a sociedade a experimentar o equilíbrio entre as relações homem-sociedade-natureza, com o propósito de promover a melhoria da qualidade de vida e a sustentabilidade, por meio da sua condição de mediadora entre o contexto educacional e o campo ambiental, favorecendo reflexões, métodos e experiências para a construção de novas bases de conhecimento e valores ecológicos para esta e para as futuras gerações.

Isso posto, pode-se dizer que os espaços voltados ao trabalho da Educação Ambiental, consistem, em contextos privilegiados, para explorarmos a vivência do corpo a partir de uma perspectiva mais ampla, como experiência da carne. O corpo, como carne do mundo, ou seja, como continuidade entre nós e o mundo, é onde acontecem as nossas experiências sensoriais com o meio ambiente e possibilita vivermos novas experiências com o próprio corpo e com o mundo, estabelecendo novas relações e atribuindo novos sentidos e significados para a carne. Isso porque assim como nós somos o mundo, nós somos a natureza.

Partindo desse pressuposto, essas experiências não podem ter como finalidade apenas a aquisição de um conhecimento sobre algo visto como externo a nós, pois as experiências com o meio ambiente consistem, nessa perspectiva, em experiências de autoconhecimento. Assim sendo, há necessidade de se compreender que é no corpo que a experiência da aprendizagem acontece. E essa compreensão é fundamental ao se propor que a Educação Ambiental promova a construção de uma nova relação homemnatureza/ homem-mundo, pois é por meio da experiência que cada pessoa toma consciência de que integra um ecossistema social e natural, o que favorece o desenvolvimento de vínculos emocionais com a natureza e do sentimento de pertença (NEUENFELDT; MAZZARINO, 2016).

Ressalta-se, portanto, a importância de reconquistarmos a relação com a natureza e os lugares, de dar significado aos espaços e cuidar dos mesmos, começando pelo próprio corpo e se estendendo ao meio ambiente, do qual somos parte integrante e o qual também habitamos (LUCENA; SOUSA, 2009; 
NEUENFELDT; MAZZARINO, 2016). Nessa direção, destaca-se, por exemplo, o movimento de revalorização das práticas esportivas ao ar livre, em conexão com a natureza, e até mesmo com as cidades e suas ruas, ou seja, com o meio ambiente como um todo, em detrimento da cultura de práticas esportivas em espaços fechados, mediante exercícios repetitivos e com pouco significado, por exemplo.

Portanto, reafirma-se que a Educação Ambiental se constitui como espaço no qual se pode proporcionar aos sujeitos a vivência do corpo e a experiência da carne em suas mais diversas dimensões, considerando a transversalidade e a inter-relação entre os temas corpo e o meio ambiente.

\section{Considerações finais}

Pode-se dizer que o nosso corpo é impregnado pelos padrões culturais e pelas relações de poder vigentes na sociedade. Isso porque o corpo se constitui na medida em que experimenta essas relações, já que é carne do mundo, ou seja: somos o que vivemos, somos seres-no-mundo. Uma vez que o mundo só possui sentido em sua relação com o humano, assim como o humano também só se constitui na relação com o outro e com o mundo, salienta-se, portanto, tanto o papel da natureza, quanto da cultura nesse processo. E, uma vez que o mundo cultural se entrelaça ao sensível e todo ser cultural se constrói nessa relação, pode-se dizer que há também uma continuidade entre a natureza humana corporal e as instituições culturais (SAENZ, 2006).

Partindo do pressuposto que a educação consiste em um meio pelo qual a cultura e as relações de poder tocam os nossos corpos, a experiência da carne vivenciada em contextos educacionais, nos quais a compreensão da continuidade entre o corpo e o mundo seja mais contemplada, pode nos favorecer a estabelecer relações com a natureza a partir de uma perspectiva mais sustentável e menos utilitarista. Nesse sentido, Saenz (2006) ainda ressalta que Merleau-ponty rechaçou o uso da razão como poder estratégico para explorar os recursos naturais e reduzir a natureza à condição de matéria-prima. Para o filósofo, a natureza consiste em um meio dinâmico, que nos envolve externa e internamente, fazendo parte de nós, assim como somos parte dela. Nessa dinâmica, o corpo, em seu caráter objetivo/subjetivo, se estabelece como nossa conexão com o mundo.

Desse modo, experimentar o nosso corpo como aquilo que somos e por meio do qual se habita o mundo, compreendendo esse corpo como carne do mundo, nos possibilita uma vivência mais consciente das nossas experiências e, consequentemente, mais crítica e questionadora dos padrões culturais e das relações de poder que influenciam as nossas atitudes e crenças em relação a nós mesmos, ao outro e ao meio ambiente, bem como os nossos comportamentos. Ratificando assim, os nossos corpos como seres-nomundo e como formas de estar-no-mundo. 
Com relação a educação escolar, ressalte-se que, ao levar em conta que corpo, natureza e cultura se interpenetram, considerando que o corpo é uma construção biocultural - um corpo vivo, ativo -, repensar o corpo na escola implica compreender que ele não pode ser apenas visto como instrumento das práticas educativas ou como objeto de programas de promoção de saúde e/ou lazer nas aulas de campo sobre Educação Ambiental, por exemplo. A experiência dos cuidados e das diferentes formas de se relacionar com o corpo, com o outro e com o meio ambiente pode, e deve, ser trabalhada transversalmente, nas diferentes práticas educativas propostas nos currículos e viabilizados pelas escolas, em suas diferentes disciplinas ofertadas (MENDES; NÓBREGA, 2004). Nessa premissa, os PCNs enfatizam a relevância dos temas transversais, tais como a Educação Ambiental, ao afirmarem que "o compromisso com a construção da cidadania pede necessariamente uma prática educacional voltada para a compreensão da realidade social e dos direitos e responsabilidades em relação à vida pessoal, coletiva e ambiental” (BRASIL, 1997, p. 15).

Salienta-se que esse processo de mudança com relação às nossas formas de ser-no-mundo e estarno-mundo passa, não só pelos alunos, mas também pelos professores e demais atores do processo educativo, considerando a necessidade de compreenderem o corpo-próprio como aquilo que nós somos e experimentarem também a carne a partir de uma outra perspectiva, proporcionada pela consciência da sua relação de continuidade com o mundo, para assim, ressignificarem as suas concepções e práticas, favorecendo a abertura de mais espaços para que os alunos também possam experimentar essa carne de outras formas, o que compreende vivenciar experiências que os levem a refletir, questionar e reelaborar suas ideias sobre as individualidades e sobre os corpos, bem como sobre a sociedade, seus padrões e sua diversidade cultural.

Ainda acerca da continuidade entre o homem e o mundo, Saenz (2006) lembra que, valorizar a experiência dessa relação requer a afirmação das diferenças e da diversidade, porque só assim pode haver respeito e cuidado do outro, de si próprio e do mundo. Isto posto, não basta à Educação Ambiental difundir o respeito à natureza, mas é necessário revelar, por meio da experiência da carne, o real alcance que essa proposta possui.

Nesse contexto, ressalta-se, mais uma vez, que a Educação Ambiental se destaca como espaço para proporcionar a experiência da carne e promover reflexões críticas, no sentido de ressignificar relações ainda vistas a partir de uma perspectiva dualista, tais como: corpo/mente, padrões/diversidade, homem/sociedade, homem/natureza e meio ambiente/sustentabilidade, por exemplo, despertando formas mais conscientes de ser-no-mundo e estar-no-mundo, para que possamos compreender a continuidade das relações entre o corpo e o mundo, e, consequentemente, entre o homem e a natureza. 


\section{Referências}

BRASIL. Ministério da Educação e Cultura. Parâmetros curriculares nacionais: Meio ambiente, saúde. Brasília, 1997.

DAOLIO, Jocimar.; RIGONI, Ana Carolina Capellini; ROBLE, Odilon José. Corporeidade: o legado de Marcel Mauss e Maurice Merleau-Ponty. Pro-posições, Campinas, SP, v. 23, n. 3, p. 179-193, set./dez. 2012. Disponível em: 〈http://www.scielo.br/pdf/pp/v23n3/11.pdf >. Acesso em: 27 abr. 2020.

FOUCAULT, Michel. Microfísica do poder. Rio de janeiro, RJ: Graal, 1984.

FOUCAULT, Michel. O sujeito e o poder. In RABINOW, P.; DREYFUS, H. (Org.). Michel Foucault: uma trajetória filosófica. Rio de Janeiro, RJ: Forense Universitária, 2009, p. 231-248. Disponível em: <https://faccaoficticia.noblogs.org/files/2015/08/O-Sujeito-e-o-Poder-Foucalt.cleaned.pdf $>$. Acesso em: 29 abr. 2020

FOUCAULT, Michel. Vigiar e punir: nascimento da prisão. Petrópolis, RJ: Vozes, 1987.

GONÇALVES, Maria Augusta Salin. Sentir, pensar e agir: corporeidade e educação. Campinas, SP: Papirus, 2001.

LÓPEZ-LÓPEZ, Mariana Alonso; GALDINO, Graciele Ribeiro. A potência do corpo e da corporeidade nas práticas e vivências educativas. Revista Interinstitucional Artes de Educar, v. 06, n. 01, p. 119-140, jan./abr. 2020.

LOURO, Guaciara Lopes. (2014). Gênero, sexualidade e educação: uma perspectiva pós-estruturalista. Petrópolis, RJ: Vozes, 2014.

LUCENA, Ricardo de Figueiredo; SOUSA, Elimar Maria Neves. Civilização e meio ambiente: notas iniciais. In: XII SIMPÓSIO INTERNACIONAL PROCESSO CIVILIZADOR. 2009, Recife, PE. Anais do Simpósio Internacional Processo Civilizador. Recife, PE: Fundação Joaquim Nabuco, 2009. Disponível em: $\quad$ http://www.uel.br/grupo-estudo/processoscivilizadores/portugues/sitesanais/anais12/index.html > Acesso em: 27 abr. 2020.

MERLEAU-PONTY, Maurice. Conversas - 1948. São Paulo, SP: Martins Fontes, 2004.

MERLEAU-PONTY, Maurice. Fenomenologia da percepção. São Paulo, SP: Martins Fontes, 1999

MERLEAU-PONTY, Maurice. O visível e o invisível. São Paulo, SP: Perspectiva, 1992. Disponível em: $<$ http://search.ebscohost.com/login.aspx?direct=true\&db=cat06476a\&AN=ufp.198231\&lang=pt br\&site=eds-live $>$. Acesso em: 17 jun. 2020.

MAlAVOLTA, Ana Paula Parise; RIGUE, Fernanda Monteiro; BIAZUS, Camilla Baldicera. Em defesa de um corpo-potência: notas sobre educação e política. Revista Interinstitucional Artes de Educar, v. 06, n. 01, p. 92-118, jan./abr. 2020.

NEUENFELDT, Derli Juliano; MAZZARINO, Jane Márcia. O corpo como lugar onde a experiência da educação ambiental nos toca. Revista Eletrônica do Mestrado em Educação Ambiental, Rio Grande, RS, v. 33, n. 1, p. 22-36, jan./abr. $2016 . \quad$ Disponível em: <https://periodicos.furg.br/remea/article/view/5309/3592>. Acesso em: 27 abr. 2020.

NÓBREGA, Trezinha Petrucia. Corporeidade e Educação Física: do corpo objeto ao corpo sujeito. Natal, RN: EDUFRN, 2005.

OLIVEIRA, Rayane Monalisa da Nóbrega.; MEDEIROS, Rosie Marie Nascimento de. A estética como perspectiva de ensino na educação física escolar: um diálogo com alunos do ensino médio. Conexões: revista da Faculdade de Educação Física da UNICAMP, v. 12, n. 03, p. 01-17, jul./set. 2014. 
PORPINO, Karenine de Oliveira. Dança é educação: interfaces entre corporeidade e estética. Natal, RN: EDUFRN, 2018.

SÄENZ, Maria Carmen López. Naturaleza y carne del mundo. Aportaciones de Merleau-Ponty a la ecofenomenología. Ludus Vitalis, v. XIV, n. 26, p. 171-186. 2006.

SANTOS, Luiz Anselmo Menezes. Educação, cultura e corporeidade: um olhar a partir da perspectiva fenomenológica de Merleau-Ponty. Revista Tempos E Espaços Em Educação, v. 7, n. 13, p. 165-176, mai./ago. 2016. Disponível em: 〈https://seer.ufs.br/index.php/revtee/article/view/3265/2884>. Acesso em: 27 abr. 2020.

SILVA, Liege Monique Filgueiras da; PORPINO, K.arenine de Oliveira. Os sentidos da beleza: discutindo as aparências do corpo na educação física. Efdeportes.com, n. 144, mai. 2010. Disponível em: <https://www.efdeportes.com/efd144/as-aparencias-do-corpo-na-educacao-fisica.htm>. Acesso em 29 abr. 2020.

Recebido em: 30/04/2020.

Revisões requeridas em: 04/06/2020.

Aceito em: 03/08/2020.

Notas:

i Possui graduação em Psicologia (Licenciatura e Formação de Psicólogo) pela Universidade Federal da Paraíba (2007). É mestre em Psicologia pela Universidade Federal da Paraíba (2010) e, Doutora em Psicologia Social (2013), pela mesma instituição, com ênfase nas áreas de Interação Social, Linguagem e Desenvolvimento Infantil. Atualmente, é Professora efetiva no Centro de Educação e Saúde - CES, lotada na Unidade Acadêmica de Saúde (UAS), da Universidade Federal de Campina Grande (UFCG). E-mail: deborahdornellas@gmail.com Campina Grande. ORCID: https://orcid.org/0000-0001-7865-5945 